\title{
REFERENCE: An APPLE II package for storage and retrieval of journal references
}

\author{
D. V. M. BISHOP \\ Neuropsychology Unit, Radcliffe Infirmary, Oxford OX2 6HE, England
}

\begin{abstract}
The package described here enables the user to maintain a "card index system" of journal references on floppy disk, with easy retrieval of references by author, subject, or combination of subjects.
\end{abstract}

Many scientists maintain a card index system of journal references. The organization of such a system can pose a problem. To file references alphabetically by author makes for easy access to a particular reference, but it is cumbersome if one wants quickly to locate all references relevant to a given topic. Filing by topic avoids this problem, but this does not work efficiently for references that are relevant to more than one topic. These problems can be overcome by using a microprocessor to store on random-access files the information that wouid normally be kept on index cards. The computer package described here enables the user to maintain a "card index system" on floppy disk, with easy retrieval of references by author, subject, or combination of subjects.

Of course, in many respects, such programs cannot compete with the large library search systems now available in many universities. The microprocessor searches comparatively slowly, and one has available only those references that have been typed in. The program package described here would not be costeffective for someone who found typing laborious and did not have secretarial help.

Two advantages of having a personalized index system based on a microcomputer are cost and availability. Perhaps the most useful aspect is the facility to develop a reference system coded to personal specifications. The subject codings used by library search systems are rational and fairly comprehensive, but they seldom correspond to the optimal partitioning of the topic for any one specialist. Using the computer package described here, a set of references can be coded into as many subject categories as one wishes. The categories can be as broad or narrow as the user desires, and idiosyncratic categories (e.g., a classification of articles in terms of methodology, as well as subject matter) are

This work was supported by MRC Grant G973/144/C. The program is available from the author at the Neuropsychology Unit, Neurosciences Group, Radcliffe Infirmary, Woodstock Road, Oxford OX2 6HE, England, for $\$ 15$ Sterling, including postage and disk. Money orders should be made payable to the Neuropsychology Unit Research Fund. possible. Furthermore, additional categorizations can be incorporated (e.g., coding whether the user has a reprint of the article, where the journal is located, or whether the article in question is good, bad, or indifferent).

\section{SYSTEM REQUIREMENTS}

The programs require an APPLE II microprocessor with $48 \mathrm{~K}$ of memory and two disk drives. A printer is extremely useful but not essential. The programs are written in APPLESOFT BASIC.

\section{HOW THE PACKAGE WORKS}

One program, CODING FILE, is used only once, to set up codings for journals, book publishers, and subject categories before using the main program, INDEX, for the first time. Codings are stored at the end of the INDEX program as a series of DATA statements. CODING FILE takes the tedium out of this operation by automatically sorting journal titles, book publishers, and subject categories alphabetically and by writing these as a series of DATA statements preceded by line numbers onto text files. The EXEC command is then used to append these lines to the end of the INDEX program. INDEX can then be saved with these new lines.

\section{Sample Run of CODING FILE ${ }^{1}$}

RUN

$$
\text { CODING FILE }
$$

THIS PROGRAM SHOULD BE RUN BEFORE RUNNING

'INDEX' FOR THE FIRST TIME

TYPE IN YOUR LIST OF JOURNALS ENDING EACH

WITH 'RETURN' (MAXIMUM OF 200 JOURNALS)

DO NOT USE COMMAS OR COLONS

TYPE > INSTEAD OF ,

TYPE \# INSTEAD OF :

\section{?NEUROPSYCHOLOGIA}

?BEHAVIOR RESEARCH METHODS AND

INSTR UMENTATION

?CORTEX

?(return)

TYPE IN YOUR LIST OF BOOK PUBLISHERS ENDING EACH WITH 'RETURN' WHEN ALL ARE ENTERED PRESS 'RETURN' (MAXIMUM OF 100 BOOK PUBLISHERS) 
DO NOT USE COMMAS OR COLONS

TYPE > INSTEAD OF ,

TYPE \# INSTEAD OF :

\author{
?WILLIAMS AND WILKINS\# BALTIMORE \\ ?ACADEMIC PRESS\# NEW YORK \\ ?(return)
}

TYPE IN YOUR LIST OF SUBJECTS ENDING EACH WITH 'RETURN'

WHEN ALL ARE ENTERED PRESS 'RETURN'

DO NOT USE COMMAS OR COLONS

TYPE > INSTEAD OF ,

TYPE \# INSTEAD OF :

\author{
?HANDEDNESS \\ ?COMPUTING \\ ?BRAIN DAMAGE \\ ?CHILDREN \\ ?(return)
}

YOUR JOURNALS, BOOK PUBLISHERS AND SUBJECTS ARE NOW STORED IN TEXT FILES

YOU ARE NOW READY TO START USING THE

PROGRAM CALLED 'INDEX'

BEFORE RUNNING 'INDEX' FOR THE FIRST TIME, CARRY OUT THE FOLLOWING OPERATIONS

\author{
LOAD INDEX \\ EXEC JOURNALS \\ EXEC BOOK PUBLISHERS \\ EXEC SUBJECTS \\ SAVE INDEX
}

YOU WILL THEN BE READY TO:

\section{RUN INDEX}

The initial codings set up by CODING FILE are not immutable. It is always possible to add a new category by typing in a new DATA statement at the end of the relevant section of the INDEX program.

There is no limit to the number of subject categories, but their selection should be given careful thought. I found it useful to include both broad and narrow categories. When selecting categories, the user is not restricted to a single category when searching for references by subject. Also, the user will have the facility to search for articles on the basis of negative as well as positive categories (e.g., you can search for articles covering handedness but not children).

Before describing the INDEX program, it is necessary to describe reference file organization. Mini-floppy disks are very limited in capacity, and random-access files, which are ideal for easy access to selected files, are uneconomical in their use of space. Even with an optimal coding system, it is not possible to store many references on a single disk. This package, therefore, uses pairs of disks to store data. Information that is used to access references (i.e., authors and subject codings, as well as the journal reference and date) are stored on a file called REFERENCE in Drive 1; titles of articles, which require a great deal of storage space but are not used to retrieve articles, are stored on a TITLES file in Drive 2. Using this format, it is possible to store approximately 530 references on a pair of mini-floppy disks. A further feature to maximize easy access is that both types of files are labeled by the initial letter of the first author (e.g., REFERENCE A, REFERENCE B, etc.). Thus, with large collections of references, files corresponding to different letters of the alphabet are stored on separate pairs of disks (e.g., REFERENCE A to REFERENCE D on one disk, with TITLES A to TITLES D on a corresponding disk; REFERENCE $E$ to REFERENCE $H$ on another, etc.). Should the number of references expand unexpectedly, it is easy to transfer a pair of files to a new disk using the TRANSFER program. This system is quite workable with a set of some 4,000 references, currently held on 10 disk pairs, which leaves a lot of room for expansion.

When INDEX is RUN, the user is instructed to put the appropriate REFERENCE disk in Drive 1 and TITLES disk in Drive 2 and is then presented the following menu:

WRITE IN NEW REFERENCE (1)

WRITE TO NUMBERED RECORD (2)

SEARCH FOR REFERENCE BY AUTHOR (3)

SEARCH FOR REFERENCE BY SUBJECT (4)

SEARCH FOR ANY OCCURRENCE OF AUTHOR (5)

PRINT OUT NUMBERED REFERENCE (6)

PRINT OUT WHOLE FILE (7)

PRINT OUT JOURNAL CODINGS (8)

PRINT OUT SUBJECT CODINGS (9)

END (10)

Write in New Reference: Sample Run

YOU WILL NOW BE ASKED TO TYPE IN DETAILS FOLLOW EACH WITH 'RETURN'

FIRST ENTER THE AUTHORS

TYPE IN EACH SURNAME FOLLOWED BY INITIALS THEN PRESS 'RETURN'

DO NOT USE COMMAS

INSTEAD OF A COMMA USE '>’

WHEN YOU HAVE TYPED IN ALL AUTHORS, JUST

PRESS 'RETURN' TO SIGNAL YOU ARE READY TO GO ON.

AUTHOR? KRASHEN $>S$. AUTHOR? (return)

DATE? 1975

NOW ENTER TITLE

(IF ARTICLE IS IN A BOOK OR UNCODED JOURNAL, ADD THESE DETAILS AT THE END OF THE TITLE, IF THE WHOLE ENTRY DOES NOT EXCEED 200 CHARACTERS)

TITLE? THE CRITICAL PERIOD OF LANGUAGE ACQUISITION AND ITS POSSIBLE BASIS

NOW ENTER REFERENCE CODING

USE THE FOLLOWING FORMAT:

FOR JOURNAL ARTICLES

$\mathrm{J}>\mathrm{V}>\mathrm{P} 1-\mathrm{P} 2$

WHERE J IS CODE NUMBER OF JOURNAL $\checkmark$ IS VOLUME NUMBER P1 AND P2 ARE PAGE NUMBERS

FOR BOOK PUBLISHER, JUST TYPE IN CODE NUMBER 
FOR DETAILS OF BOOK NOT INCLUDED IN TITLE, TYPE 'B'

FOR UNPUBLISHED ARTICLES TYPE ' 200 '

IF ALL DETAILS ALREADY SPECIFIED WITH TITLE, TYPE ' 0 '

$? 13>263>211-224$

NOW ENTER SUBJECT CODING

TYPE ALL RELEVANT CODE NUMBERS SEPAR ATED BY SPACES, THEN PRESS 'RETURN'

CODING? 2436107

NOW CHECK THIS ENTRY

FOR EACH PIECE OF INFORMATION, PRESS 'RETURN'

IF ALL OK, PRESS ANY OTHER KEY IF NOT

CODING

$\begin{array}{lll}24 & 36 & 107\end{array}$

?(return)

DATE

1975

?(return)

REFERENCE CODE

?(return)

$13>263>211-224$

AUTHORS

?(return)

KRASHEN $>$ S.

TITLE

THE CRITICAL PERIOD OF LANGUAGE

ACQUISITION AND ITS POSSIBLE

BASIS

$? N$

CORRECT TITLE?

THE CRITICAL PERIOD FOR LANGUAGE

ACQUISITION AND ITS POSSIBLE BASIS

TITLE

THE CRITICAL PERIOD FOR LANGUAGE

?(return)

ACQUISITION AND ITS POSSIBLE BASIS

NOW WRITING REFERENCE ON DISK

RECORD NO. 173

DO YOU WANT TO ENTER ANOTHER $(\mathrm{Y} / \mathrm{N})$ ?

The reference is written onto the next record on the REFERENCE file. The total number of records on the file is stored in Record 0 . References occurring in books must be handled separately, since codings are not available for books. A space-saving way is to add the book details to the end of the title and then give the code 0 for journal reference. If the book details are too long, then the user can specify $B$ in response to the request for a journal code, and he is then able to type in the book details, which are saved on a separate file called BOOKS $\$$, where $\$$ is the initial letter of the first author's name.

\section{Write to Numbered Record}

This option is similar to the first (write in new reference) but it allows the user to select the record number of the reference and to overwrite old references if he wishes.
Search for Particular Reference: Sample Run

NOW SPECIFY AUTHORS. SEARCH WILL ONLY FIND AUTHORS IN CORRECT ORDER.

YOU NEED NOT SPECIFY INITIALS, BUT IF YOU DO, ADOPT THE FOLLOWING FORMAT: BISHOP $>$ D.V.M.

WHEN ALL AUTHORS ENTERED, TYPE 'RETURN' IN RESPONSE TO THE 'AUTHOR' PROMPT

AUTHOR? LURIA
AUTHOR? (return)

Any references in the system with Luria as sole author will now be printed on the screen. The user has the option of printing out references if he or she wishes.

Search for Reference by Subject: Sample Run

1 AND 2

THIS IS SEARCH COMMAND, DO YOU WANT TO CHANGE IT?

TYPE 'Y'OR ' $N$ '

IF YOU DON'T KNOW WHAT A SEARCH COMMAND IS, TYPE ' $Y$ '

$? Y$

REPLACE MAIN DISK IN DRIVE 1, THEN PRESS 'RETURN'

?(return)

YOU MUST NOW SPECIFY A SEARCH STRING. USE CONSECUTIVE NUMBERS 1,2,3 ETC TO DENOTE

SUBJECT CATEGORIES

DO YOU WANT TO SEE SOME EXAMPLES OF SEARCH STRINGS?

$? \mathrm{~N}$

NOW TYPE IN SEARCH STRING

? $A N D$ (2 OR 3)

TO CONTINUE, NOW TYPE THE FOLLOWING COMMANDS EXACTLY AS SHOWN BELOW,

FOLLOWING EACH WITH 'RETURN'

(WAIT UNTIL THE DISK DRIVE LIGHT IS OUT BEFORE STARTING COMMAND 2)

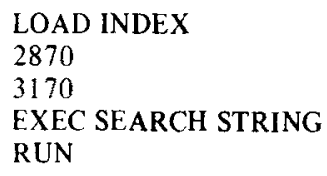

LOAD INDEX

2870

3170

EXEC SEARCH STRING

$R U N$

PUT REFERENCE DISK IN DRIVE 1 AND TITLES DISK IN DRIVE 2

PRESS 'RETURN' WHEN READY TO CONTINUE ?(return)

1 AND (2 OR 3)

THIS IS SF ARCH COMMAND. DO YOU WANT TO

CHANGEIT? 
TYPE ' $Y$ ' OR ' $N$ '

IF YOU DON'T KNOW WHAT A SEARCH COMMAND IS, TYPE ' $Y$ '

$? N$

\section{SUBJECT CODE CORRESPONDING TO 1 ? 31 \\ SUBJECT CODE CORRESPONDING TO 2? 24 \\ SUBJECT CODE CORRESPONDING TO 3? 5}

\section{TYPE IN IDENTIFYING LETTER OF REFERENCE \\ FILE? $D$}

\section{SEARCH WILL TAKE A MINUTE OR TWO, DEPENDING ON FILE LENGTH. I WILL CALL YOU WHEN I AM READY}

The search is conducted one file at a time, with relevant references being printed on the screen after each file is searched. The program then stops to allow the user to specify a new file and, if necessary, to insert a new pair of disks. The time taken to search through the whole reference collection will obviously depend on the number of disks involved, the complexity of the search command, and the number of references found. The user has the option of having each reference printed on the screen and then selecting those he wishes to print out using the printer, or of automatically printing out hard copy of all references that are found. My collection (approximately 4,000 references on 10 disk pairs) takes an average of $30 \mathrm{~min}$ to search through completely.

\section{Search for Any Occurrence of Author}

This option is similar to the search for particular reference, but it enables the user to look for a reference in which a given person is listed as an author, irrespective of other authors.
The author searched for need not be the first author, and one can thus search files other than those beginning with the author's initial letter, if necessary searching through the whole collection of references.

\section{Print Out Numbered Reference}

When references are printed out on a screen or printer, the record number is always printed out on the top right-hand corner. If the record number of a given reference is known, then that reference can be quickly accessed and printed on the screen and/or the printer. This instruction alsc gives the user the option of correcting references that contain errors.

\section{Print Out Whole File}

All references on a file are printed out on screen and/or printer.

\section{Print Out Journal Codings}

It is necessary to have a list of journal codings when entering new references. This instruction enables the user to obtain a list of journal codings with the journals in alphabetical order.

\section{Print Out Subject Codings}

This is the same as printing out journal codings, except that the subject codings are not automatically alphabetically sorted before printout.

\section{NOTE}

1. Information entered by the user is printed in italic type.

(Received for publication December 24, 1980; accepted December 31, 1980.) 